DOI: 10.1002/adem.((please add manuscript number))

\title{
Designing Stainless Steel Surfaces with Anti-Pitting Properties Applying Laser Ablation and Organofluorine Coatings**
}

By Elaine Armelin, ${ }^{*[\mathrm{a}]}$ Sona Moradi,${ }^{[\mathrm{b}]}$ Savvas G. Hatzikiriakos, ${ }^{*[\mathrm{~b}]}$ and Carlos Alemán ${ }^{*[\mathrm{a}]}$

[a] Dr. E. Armelin and Prof. Dr. C. Alemán. Departament d'Enginyeria Química (EEBE) and Barcelona Research Center for Multiscale Science and Engineering, Universitat Politècnica de Catalunya, C/ Eduard Maristany, 10-14, Ed. I2, 08019, Barcelona, Spain.

E-mail: elaine.armelin@uipc.edu and carlos.aleman@upc.edu

[b] Dr. S. Moradi and Prof. Dr. S. V. Hatzikiriakos. Department of Chemical and Biological Engineering, The University of British Columbia, Vancouver, BC, V6T 1Z3, Canada.E-mail: savvas.hatzi@ubc.ca

[**] This work has been supported by MICINN and FEDER funds (MAT2015-69367-R). S.G.H. acknowledges support from NSERC the funding agency of Canada. C.A. acknowledges the award "ICREA Academia 2015" for excellence in research funded by the government of Generalitat de Catalunya. The authors are also grateful to Dr. M. Dominguez for her help with XPS analyses.

Supporting Information is available online from Wiley InterScience.

Abstract: Long-lasting and superhydrophobic stainless steel with anti-pitting properties is achieved by modifying conventional AISI 304L through a two-step strategy: (i) application of a femtosecond surface laser ablation treatment to generate micro-nano structures on the surface; and (ii) deposition of organofluorine nanometric coating. Samples with two different patterns, namely paraboloid- and cauliflower-like, are approached and investigated by means of contact angle hysteresis, X-ray photoelectron spectroscopy and electrochemical techniques. Results indicate that the stainless steel surface acquires efficient anticorrosive properties due to the homogenization and refinement of the patterned microstructure into a magnetite rich phase, in combination with the formation of a carbonaceous and sol-gel layer. The adherent semiconducting oxide layer is stable over time in presence of an aggressive chloride environment. The prepared superhydrophobic surfaces prevent the steel substrates from getting wet with water, protecting them from the pitting corrosion caused by the electrolyte intrusion. The corrosion resistance is explained by a mechanism in which, in 
addition of the silane coating, the air trapped into the micro-nano patterned surfaces plays an important role.

\section{Introduction}

In opposition to carbon steel and low-alloy steels, high-alloy stainless steels (SSs), which are rich on chromium and chromium/nickel elements, do not suffer active corrosion in neutral water but are aggressively attacked by chlorine or bromine salt solutions. Thus, when exposed to seawater, this kind of SSs develops deep pits, which initiate at crevices (i.e. crevice corrosion) within a few months. ${ }^{[1]}$ The susceptibility to pitting and crevice corrosion is greater in the martensitic and ferritic steels than in the austenitic ones, the resistance of the latter alloys increasing with the nickel content. Austenitic SSs are customarily used in elements produced for architectural and automobile sectors, and in equipment typically utilized by food and chemical industries. Therefore, methods to protect these surfaces from corrosion are very necessary. Pitting inhibitors, like sulfate or bicarbonate, are frequently employed to solve temporarily the problem, ${ }^{[2]}$ even though long-term approaches and more efficient alternatives are highly desirable.

Pitting and crevice corrosion processes accelerate under specific conditions, which represent a serious problem. More specifically, the pitting potential (i.e. critical potential for pitting corrosion, $\mathrm{E}_{\mathrm{pit}}$ ) shifts to more negative values by increasing the concentration of chloride ions, the oxygen content, the temperature or the presence of pollutant molecules (like $\mathrm{SO}_{2}$ and $\mathrm{H}_{2} \mathrm{~S}$ ), and by decreasing the purity of the employed metals. ${ }^{[3]}$ Fortunately, some solutions can be applied to reduce, or even avoid, this undesired phenomenon: (i) apply cathodic protection to maintain the potential below the critical pitting one; (ii) add anions (e.g. $\mathrm{OH}^{-}$or $\left.\mathrm{NO}_{3}{ }^{-}\right)$to modify the chloride environment or reduce the oxygen concentration; and (iii) regulate the operating temperature (e.g. for $304 \mathrm{~L}$ in $\mathrm{NaCl}$ solutions, keep the operating temperatures below $\left.60-80{ }^{\circ} \mathrm{C}\right) .{ }^{[4]}$ 
A well-stablished method to protect metals is the formation of a compact, thick and homogenous passive layer, for example, by an anodizing process in aluminum or by chromium conversions treatments in SS, aluminum, copper metal and other surfaces. ${ }^{[1-4]}$ However, these methods are not protective enough for increasing exposure to aggressive environment since the stable passive layer can break down. Thus, the rate of corrosion increases with the ease with which corrosive ions reach the anodic iron zone. Another approach is the creation of a physical barrier between the electrolyte and the SS surface. However, either organic or inorganic coatings are not completely impermeable to the penetration of oxygen and chlorine ions under severe conditions. Additionally, the presence of microscopic pores or cracks in coatings promotes the pitting corrosion in SS. The adherence of the coating is other critical point to protect SS substrates. ${ }^{[5]}$ In summary, coating materials cannot be considered as an efficient long-lasting solution for long time exposure to aggressive environments.

New approaches and technologies are necessary to address this serious problem. Several authors have reported the benefits of laser treatments for improving the surface resistance of SS against corrosion. ${ }^{[6,7]}$ Pacquentin et al. ${ }^{[6]}$ reported the successful effect of beam overlap on pitting corrosion resistance of AISI 304L SS. This improvement was attributed to both the enrichment of the chromium percentage on the surface of the SS (47 wt. \%) and the absence of martensite and ferrite phases, both confirmed by X-ray diffraction analyses. ${ }^{[6]}$ Besides, some of us reported that, while femtosecond laser irradiated SS surfaces initially show superhydrophilic behavior, over time they become gradually superhydrophobic. ${ }^{[8]}$ This was attributed to the decomposition of carbon dioxide from the ambient air into carbon with active magnetite, as corroborated by XPS analysis, ${ }^{[8]}$ and also reported in earlier studies. ${ }^{[9]}$ The presence of this oxide combined with the carbonaceous layer deposited from the catalytic reactions could provide corrosion resistance to SS substrates. Moreover, this strategy can be combined with water-repellent coatings, as for example hydrophobic organoalkylsilanes, ${ }^{[10]}$ 
which are promising candidates for anti-icing, anti-adhesion and self-cleaning applications. ${ }^{19}$ For example, patterned surfaces fabricated with surface laser ablation (SLA) were transformed into highly superhydrophobic by applying a monolayer of a fluoroalkylsilane compound. $^{[12]}$

The approach used in this work to create corrosion resistant AISI 304L SS substrates is based on inducing surface roughening through a laser surface micro-patterning treatment and on the subsequent application of a nanometric coating prepared using low-surface energy chemicals. More specifically, the aim of the present study is to investigate the corrosion and passivity resistance of AISI 304L SS substrates with two different and well-defined hydrophobic patterns, which have been induced by SLA conversion and subsequently protected with organic-inorganic coating. For this purpose, the corrosion resistance of all prepared samples, which have been characterized by different spectroscopic techniques and scanning electron microscopy (SEM), has been evaluated in $\mathrm{NaCl} 3.5$ wt. \% solution using electrochemical impedance spectroscopy (EIS) and potentiodynamic experiments.

\section{Methods}

\subsection{Materials}

AISI 304L SS discs, $32 \mathrm{~mm}$ in diameter and $1 \mathrm{~mm}$ in thickness, were used as substrates in this work. They were polished using sandpaper (grit P60 to P1200) to reach an average roughness value $\left(R_{a}\right)$ of about $500 \mathrm{~nm} . R_{a}$, which is defined as the average length of protrusions above their mean value, was measured using a DEKTAK profilometer.

In order to render substrates with low surface energy, the surface chemistry was modified by applying trichloro(1H, 1H, 2H, 2H-perfluorooctyl)silane, abbreviated FOTS (97\%, SigmaAldrich, USA), using the dip-coating method.

\subsection{Surface laser irradiation}


Femtosecond laser treatment was used to produce patterned metallic surface. Ultrashort laser pulses to irradiate various substrates were generated by an amplified solid-state Ti : Sapphire laser. The laser system includes a Ti : Sapphire seed laser Coherent Mira HP and an amplifier Coherent Legend to produce amplified femtosecond laser pulses with center wavelength of $800 \mathrm{~nm}$. The repetition rate of laser pulses $(f)$ was $1 \mathrm{kHz}$ with pulse duration of $120 \mathrm{fs}$ and the maximum output power of about $2 \mathrm{~W}$. The beam profile from this regenerative amplifier system has a Gaussian distribution with a beam waist of $10 \mathrm{~mm}$. A set of neutral density (ND) filters were used to attenuate and adjust the energy of the laser beam and a lens with $300 \mathrm{~mm}$ focal length was used to focus the beam on the sample. The spot size of beam at the focal point $\left(2 \omega_{0}\right)$ was $30 \mu \mathrm{m}$.

In order to translate the samples under the laser beam, the SS sheets were mounted on a precise computer-controlled ZABER T-LS80 X-Y translation stage. The power of the incident laser beam was adjusted in the range of 5 to $1700 \mathrm{~mW}$ (peak fluence, $\Phi_{0}: 1.4$ to $480 \mathrm{~J} / \mathrm{cm}^{2}$ ) and the scanning speed varied from 250 to $1850 \mu \mathrm{m} / \mathrm{s}$. Samples were irradiated at normal incidence in air and then subjected to an ultrasonic bath for 2 min in acetone to remove all the debris off the patterned surface.

\subsection{Sol-gel deposition by dip-coating}

In order to remove any contamination and expose the hydroxyl groups $(-\mathrm{OH})$ on the surface, SS samples were pretreated using a piranha solution composed of $\mathrm{H}_{2} \mathrm{SO}_{4} / \mathrm{H}_{2} \mathrm{O}_{2}(4: 1 \mathrm{v} / \mathrm{v})$ for 1 $\mathrm{h}$ at room temperature. After acid treatment, the surfaces were exhaustively rinsed with ethanol, water and acetone respectively for 10 minutes in ultrasonic bath. After cleaning and blowing of nitrogen for drying, samples were subjected to the silanization step. For this purpose, SS plates were immersed in $n$-hexane with $0.5 \%$ wt. FOTS $(0.075 \mathrm{~g}$ per $10 \mathrm{~mL}$ of $n$ hexane) for $2 \mathrm{~h}$ at $60^{\circ} \mathrm{C}$. Hydrolysis and hydrogen bonding formation occurs at this step. Then, silane films were dried with nitrogen and heated for $1 \mathrm{~h}$ at $120^{\circ} \mathrm{C}$ in an oven. After this 
step, silane films were rinsed in distilled water for 2 min to remove any weakly bounded or adsorbed species.

The sequence of steps for obtaining AISI 304L SS superhydrophobic surfaces is schematically summarized in Fig. 1.

\subsection{Surface analysis}

The wetting behavior of the irradiated samples was evaluated by measuring the contact angle (CA) with deionized water (resistivity of $18.2 \mathrm{M} \Omega \cdot \mathrm{cm}$ at $25^{\circ} \mathrm{C}$ ). Static CAs were determined with the sessile drop method. ${ }^{[13]}$ Water droplets of $4 \mu \mathrm{L}$ were dispensed on the respective surfaces with a piston-driven air displacement pipette. Digital images of the water droplet on the surfaces were taken with a Nikon D90 digital camera. The CA values were determined by analyzing droplet images with an image processing method of MATLAB. Measurements of the advancing and receding CA values of a growing and shrinking droplet on the surface were performed to obtain the contact angle hysteresis (CAH). The CA measurements were repeated 5 times for each surface at different locations to check for uniformity of the surface properties. Standard deviation errors were lower than $2^{\circ}$ in all cases.

In order to map the geometrical characteristics of the micro-nanopatterned surfaces, the morphology of the surface structures fabricated by laser ablation was studied by Scanning Electron Microscopy (SEM) using a variable-pressure Hitachi S-3000N scanning electron microscope (University of British Columbia) and by profilometry (Bruker, Dektak XT). Additional SEM studies were carried out on the tested samples, before and after the corrosion experiments. For this purpose, a Focused Ion Beam Zeiss Neon 40 scanning electron microscope (Universitat Politècnica de Catalunya) equipped with energy dispersive X-ray spectroscopy (EDS) analysis and operating at $30 \mathrm{kV}$ was employed.

The silane and oxide layers were evaluated by FTIR spectroscopy using a Nicolet 6700 FT-IR spectrometer equipped with a Smart SAGA (Specular Aperture Grazing Angle) accessory and 
Omnic software. Spectra were collected with an incidence angle of $80^{\circ}$ from the normal surface at a resolution of $8 \mathrm{~cm}^{-1}$ (accumulating 120 scans) with a polished gold substrate as background.

The surface composition was evaluated by X-ray photoelectron spectroscopy (XPS). Analyses were performed in a SPECS system equipped with a non-monochromated twin anode X-ray source XR50 of $\mathrm{Mg} / \mathrm{Al}(1253 \mathrm{eV} / 1487 \mathrm{eV})$. Specifically, the $\mathrm{Al}$ anode was used as X-ray source operating at $150 \mathrm{~W}$, and a Phoibos $150 \mathrm{MCD}-9 \mathrm{XP}$ as detector. The pass energy was set to 25 and $0.1 \mathrm{eV}$ for the survey and the narrow scans, respectively. The $\mathrm{C} 1 \mathrm{~s}$ peak was used as internal reference with a binding energy of $284.5 \mathrm{eV}$. High-resolution XPS spectra were acquired by Gaussian-Lorentzian curve fitting after S-shape background subtraction.

\subsection{Corrosion testing}

Polarization curves and EIS experiments were performed with a potenciostat-galvanostat Autolab PGSTAT302N, equipped with the ECD module (Ecochimie, The Netherlands) and with a three-electrode cell. $\mathrm{The} \mathrm{Ag} \mid \mathrm{AgCl}$ electrode $(\mathrm{KCl}, 3 \mathrm{M})$ was used as the reference electrode, whereas unpatterned and patterned SS specimens were used as working electrodes (working area of $0.7854 \mathrm{~cm}^{2}$ ). A platinum foil was used as the counter electrode in all cases.

The corrosive medium was $\mathrm{NaCl} 3.5$ wt. \% (250 mL) for both polarization and EIS assays. Polarization analyses were carried out using a polarization range from $-1.0 \mathrm{~V}$ to $+0.8 \mathrm{~V}$ and a scan rate of $1 \mathrm{mV} / \mathrm{s}$. Potentiodynamic studies were performed after sample stabilization to the open circuit potential (30 min). For EIS assays, the frequency was varied between $10 \mathrm{mHz}$ to $1 \mathrm{kHz}$, while the amplitude of the sinusoidal voltage was $10 \mathrm{mV}$. Experiments were performed on as prepared samples and samples immersed 1, 2 and 7 days in $\mathrm{NaCl} 3.5$ wt. \%. The corrosion potential $\left(\mathrm{E}_{\mathrm{OCP}}\right)$ was also monitored.

\section{Results and discussion}




\subsection{Evaluation of the paraboloidal and cauliflowered patterns}

Surface patterns are regulated by the laser beam peak fluence $\left(\Phi_{0}\right)$, which corresponds to the energy delivered per unit area, and scanning speed $(V)$. In this work we have focused on two surface patterns, namely paraboloidal and cauliflowered patterns, which exhibit the most interesting behavior in terms of wettability. Fig. 2 depicts SEM images of these patterns at three levels of magnification. The paraboloidal pattern, which was obtained using $\Phi_{0}=16$ $\mathrm{J} / \mathrm{cm}^{2}$ and $V=460 \mu \mathrm{m} / \mathrm{s}$, exhibits a pillared morphology with paraboloidal microbumps (Fig. 2a). Higher magnifications of the sample reveal that this laser induced surface pattern consists of micro-paraboloids (Fig. 2b-c), which are covered with approximately hemi-cylindrical nanoscaled ripples. On the other hand, the cauliflower-like pattern, which was produced using $\Phi_{0}=135.8 \mathrm{~J} / \mathrm{cm}^{2}$ and $V=930 \mu \mathrm{m} / \mathrm{s}$, clearly resembles the surface of cauliflower (Fig. 2d-f). This pattern consists of an essentially triple roughness structure with re-entrant micro-pillar size in the range of 50 to $100 \mu \mathrm{m}$.

Superhydrophobicity is induced by a micro/nanoscale structure combined with a low surface energy coating, which results in very high water CA (i.e. $\left.\geq 150^{\circ}\right)$ and low CA hysteresis (i.e. $\left.\leq 5^{\circ}\right) .{ }^{[12 \mathrm{a}]}$ The wettability of samples with paraboloidal and cauliflowered patterns was tested after the deposition of the silane monolayer. The fluoroalkylsilane agent has the function of decrease the surface energy of the laser irradiated microstructures. For comparison, flat SS samples with and without silanization were also tested (control surfaces). Table 1, which lists the CA values and the CA hysteresis, indicates that the surface hydrophobicity increases by a factor of 1.35 with the silanization, whereas if the surface is modified by laser irradiation plus silanization the factor increases by 1.8-2.0. The CA of the flat SS surface increased from $80^{\circ}$ to $108^{\circ}$ after silanization. Besides, the CA of the cauliflower-like pattern was $157^{\circ}$ with a hysteresis lower than $5^{\circ}$, whereas the CA and the hysteresis of the paraboloidal pattern were $145^{\circ}$ and $16^{\circ}$. These results indicate that the cauliflower-like surface fulfills the requirements of a truly superhydrophobic surface. The presence of the high frequency of nano- 
microstructures (multi-scale roughness) and also its re-entrant pattern are the reason of the very low hysteresis determined for the cauliflowered pattern. It should be noted that the smallest the CA hysteresis, the highest the droplets' mobility due to low adhesion.

\subsection{Analyses of the sol-gel coating and the oxide products obtained after SLA and corrosion assays}

Fig. 3a displays the spectrum recorded for a silanized flat SS sample. Due to the very low thickness of the FOTS coating, the spectrum presents some noise. In spite of this, several bands coming from the silane network, which is obtained after the hydrolysis of FOTS molecules and their subsequent reaction with the metal substrate, are clearly identified. More specifically, the main absorption bands of the coating are due to the vibrations of the $\mathrm{CH}_{2}$ aliphatic groups $\left(2912 \mathrm{~cm}^{-1}, 2844 \mathrm{~cm}^{-1}, 1471 \mathrm{~cm}^{-1}, 1425 \mathrm{~cm}^{-1}\right)$, the O-Si-O and C-Si-O linkages $\left(1247 \mathrm{~cm}^{-1}, 1218 \mathrm{~cm}^{-1}\right)$, and the $\mathrm{CF}_{2}$ and $\mathrm{CF}_{3}$ groups $\left(1147 \mathrm{~cm}^{-1}, 715 \mathrm{~cm}^{-1}, 707 \mathrm{~cm}^{-1}\right.$, $\left.655 \mathrm{~cm}^{-1}\right) .{ }^{[14]}$ Obviously, the FTIR spectra recorded for silanized patterned surfaces (not shown) are very similar to that displayed in Fig. 3a. Unfortunately, FTIR spectra did not allow us to confirm the presence of silane films after corrosion assays, even though this was investigated by XPS surface analyses (see below).

On the other hand, some relevant differences induced by the SLA method are detected when the composition of the oxides formed after corrosion assays are studied by FTIR (Fig. 3b). The paraboloidal patterned surface shows absorption bands at $594 \mathrm{~cm}^{-1}$ and $632 \mathrm{~cm}^{-1}$, evidencing the presence of magnetite crystalline structures $\left(\mathrm{Fe}_{3} \mathrm{O}_{4}\right) .{ }^{[15]}$ In contrast, the spectrum of the cauliflower-like patterned samples exhibit absorption bands of both magnetite and hematite $\left(\alpha-\mathrm{Fe}_{2} \mathrm{O}_{3}\right)$. Hematite peaks usually appear at lower wavenumber than magnetite (i.e. $520 \mathrm{~cm}^{-1}, 559 \mathrm{~cm}^{-1}, 590 \mathrm{~cm}^{-1}$ ). A noticeable feature is the absence of the typical akaganéite $(\beta-\mathrm{FeOOH})$ absorption bands, which usually appears as a strong and broad peak at about $3300 \mathrm{~cm}^{-1}(\mathrm{O}-\mathrm{H}$ stretching vibrations $) .{ }^{[16]} \beta-\mathrm{FeOOH}$ is considered the most damaging 
among the ferric oxyhydroxides for the corrosion resistance of steel. ${ }^{[17]}$ Akaganéite aggregates contain chloride anions $\left(\mathrm{Cl}^{-}\right)$and are associated to a non-adherent and non-protective oxide type.

In order to corroborate the previous observations, EDX semi-quantitative studies were conducted on different samples after immersion in $\mathrm{NaCl}$ solution for 7 days (Fig. S1). The most relevant result is the absence of chloride anions after the corrosion experiments. This is consistent with the characteristic stability of the passive oxide layer generated by the SLA method. ${ }^{[8,9,12 \mathrm{a}]}$ Besides, silicon atoms are present in all samples, even though it is not possible to discriminate among the $\mathrm{Si}$ atoms from silane coating and from the metal alloy due to the high penetration electron beam in SEM microscopy.

Fig. S2 and 4 compare the morphology of flat and patterned SS samples, respectively, before and after immersion in $\mathrm{NaCl} 3.5$ wt. \% for 7 days. Large agglomerates formed by iron, chromium, manganese and nickel oxides, as corroborated by EDX analyses, are detected in the pitting areas. This demonstrates that the silane coating is not impermeable enough and, therefore, does not preclude the entrance of ions. The paraboloid microstructure (Fig. 4a-b) offered more resistance to morphological changes than the cauliflower-like surface (Fig. 4cd). Spherical magnetite structures, which are homogenously obtained after SLA, are efficient to avoid the pitting corrosion of parabolidal samples, which maintained their outer microstructure. Thus, both globular and nano-rippled structures (indicated by arrows and rectangular boxes in Fig. 4a-b) are still present after immersion in $\mathrm{NaCl}$. Moreover, high magnification SEM images reveal morphological details of the paraboloidal patterned samples, which exhibit highly oriented $\mathrm{Fe}_{3} \mathrm{O}_{4}$ building blocks assembled into nanometric chain-like structures. In the case of cauliflowered pattern, the globular structures change to more irregular morphologies (indicated by rectangles in Fig. 4d). Indeed, comparison of high magnification images before and after immersion in $\mathrm{NaCl}$ (Fig. 4c-d) reveals that some spherical particles are eliminated from the surface and most of them are reduced in size, 
especially those localized in the inner wells (circles in Fig. 4d). Despite these changes, the corrosion protection imparted by the cauliflower-like pattern is not substantially affected, as proved by the EIS measurements (see below).

Undoubtedly, XPS is a powerful technique to investigate the composition of any material deposited or generated as a thin layer on a solid substrate. The X-ray penetration only reaches 10-15 nm of depth profile. For this study, three samples were compared: (i) paraboloidal silanized SS disk after a polarization assay in $\mathrm{NaCl}$ solution from -1.0 to $+1.0 \mathrm{~V}$, called “overoxidized" sample; (ii) paraboloidal silanized SS disk after immersion in $\mathrm{NaCl}$ solution for 7 days (i.e. without potentiodynamic polarization); and (iii) cauliflowered silanized SS disk after immersion in $\mathrm{NaCl}$ solution for 7 days. Inspection of the survey XPS spectra (Fig. 5a) reveals that that, in addition to iron and oxygen, the patterned samples contain a significant amount of carbon (44-54\%); as well as fluorine (34-44\%) and silicon (2-3\%) atoms. Moreover, chromium with low atomic percentage $(0.3 \%)$ was also detected (Table S1). Presumably, the carbon is adsorbed from the atmosphere (i.e. carbon dioxide or hydrocarbons), this process being promoted by the SLA treatment. The conversion of carbon dioxide into carbon with active magnetite before corrosion experiments, was previously proved ${ }^{[8,9]}$ The decomposition of $\mathrm{CO}_{2}$ into carbon on oxygen-deficient magnetite occurs through a two-step process:

$$
\begin{aligned}
& \text { Step 1: } \quad \mathrm{CO}_{2} \rightarrow \mathrm{CO}+\mathrm{O}^{2-} \\
& \text { Step 2: } \mathrm{CO} \rightarrow \mathrm{C}+\mathrm{O}
\end{aligned}
$$

The first step controls the reaction rate, the intermediate product, carbon monoxide, being rapidly converted further into zero valence carbon. ${ }^{[9 c]}$

Although the survey spectra are similar for all samples, analyses of high-resolution XPS allowed us to detect some differences. As it can be seen in Fig. 5b-d, the Fe 2p spectrum of the overoxidized paraboloidal sample has three well defined shoulders between 730 and 705 $\mathrm{eV}$, while the $\mathrm{O} 1 \mathrm{~s}$ spectrum exhibits a broad peak at $532 \mathrm{eV}$ only. Analysis of the Fe orbital 
peaks reflected two main binding energies at $711 \mathrm{eV}$ and $725 \mathrm{eV}$ coming from $2 \mathrm{p} 1 / 2$ and $2 \mathrm{p}$ $3 / 2$, respectively, a $845 \mathrm{eV}$ peak from $2 \mathrm{~s}$, and, with less significance, two peaks at $92 \mathrm{eV}$ and $53 \mathrm{eV}$ from $3 \mathrm{~s}$ and $3 \mathrm{p}$, respectively. The first two peaks are associated to $\mathrm{Fe}_{2} \mathrm{O}_{3}$ oxides, whereas the rest are typically assigned to the $\mathrm{Fe}_{3} \mathrm{O}_{4}$ magnetite composition. Besides, deconvolution of $\mathrm{O} 1 \mathrm{~s}$ spectra demonstrated that chromium atoms correspond to the $\mathrm{Cr}_{2} \mathrm{O}_{3}$ oxide. Moreover, chlorine ions were not detected either in this sample or in the other two patterned surfaces (Table S1). Overall, results indicate that the corroded area is mainly composed by $\mathrm{Fe}_{2} \mathrm{O}_{3}$ and $\mathrm{Cr}_{2} \mathrm{O}_{3}$, whereas the upper layer still maintains the organofluorine silane coating and the variety of carbonaceous compositions.

Inspection of C 1s high-resolution spectra reveals a peak at $284.8 \mathrm{eV}$, which has been associated to the gradual apparition of $\mathrm{CO}$ or $\mathrm{CO}_{2}$ species (i.e. insulating carbon) on pristine surfaces. ${ }^{[18]}$ This feature supports our assumption that carbon monoxide and zero valence carbon remains stable after exposition to $\mathrm{NaCl}$ corrosive medium. Additionally, overoxidized and immersed samples display significant differences in both $\mathrm{Fe} 2 \mathrm{p}$ and $\mathrm{O}$ 1s regions. More specifically, the atomic concentration of iron is almost negligible for samples immersed in $\mathrm{NaCl}$ for one week, independently of the pattern, whereas oxygen is assumed to belong to $\mathrm{CO}$ and $\mathrm{Cr}_{2} \mathrm{O}_{3}$ oxides (Fig. 5c-d). These features confirm that the first phase boundary is equal to the iron oxide layer deposited on the rough substrate. The roles played by this stable interface are the metal adhesion and corrosion protection. The second phase boundary, which was observed by polarization and EIS experiments (see below), is presumably the oxide/air interface inside nano/microstructure pools created by the SLA technique. Finally, the third phase boundary is the oxide/silane interface, which is responsible for the internal cohesion with the passivating oxide layer and non-wetting external layer.

\subsection{Potentiodynamic study on superhydrophobic surfaces}


In general, pitting corrosion of passivated metals only occurs when the passive film is locally destroyed. Chlorine ions are the most aggressive ions responsible for this local attack. ${ }^{[1 \mathrm{~b}]}$ Results from polarization assays are displayed in Fig. 6 and Table 2. As it can be seen, the bare flat SS substrate exhibits the lowest pitting potential $\left(\mathrm{E}_{\mathrm{pit}}\right)$, moving very fast to positive overoxidation potential and high current density after overcome the overoxidation potential $(238 \mathrm{mV})$. Besides, the silanized flat SS surface has the lowest corrosion current density and shows higher passivating interval $\left(\Delta \mathrm{E}_{\mathrm{pas}}\right)$ than the uncoated flat substrate, even though its corrosion current density ( $\mathrm{i}_{\text {corr }}$ ) starts to increase in the zone above $452 \mathrm{mV}$. In opposition, the current density experiences a slight increment for the patterned samples $\left(1.22-5.85 \times 10^{-5}\right.$ $\left.\mathrm{A} / \mathrm{cm}^{2}\right)$ with respect the silanized systems $\left(9.20 \times 10^{-7} \mathrm{~A} / \mathrm{cm}^{2}\right)$. This is due to the well- and homogenously formed oxide layer (already corroded) for the formers compared to the thick barrier coating obtained with the silane layer. However, as it can be seen in Table 2, the interval of "pseudo-passivated" zone in the patterned surfaces is higher than that in the flat and silanized ones, proving that the oxide layer offered a beneficial great passive zone at the initial stages. The largest interval $\left(\Delta \mathrm{E}_{\mathrm{pas}}=877 \mathrm{mV}\right)$ corresponds to the silanized paraboloidal sample, whereas that of the silanized flat surface is $633 \mathrm{mV}$.

Potentiodynamic results prove that, despite the corrosion potential of the metal substrate is more negative in the Tafel plot, the oxidized layer from paraboloid- and cauliflower-like microstructures (with higher corrosion current density) is more stable than the pure metal (i.e. flat substrate), which is partially passivated with chromium oxide from the austenitic alloy. This feature is corroborated by the comparison of the three silanized substrates (i.e. flat, paraboloidal and cauliflowered). The adherence to the substrate of this organic-inorganic layer probably is not enough to prevent the entrance of chloride ions. Results obtained for the silanized flat sample, which showed a pronounced increase of the current density after overcome the $\mathrm{E}_{\mathrm{pit}}$, evidenced this feature. In contrast, the current density was maintained constant until high potential values for superhydrophobic patterned surfaces. Accordingly, 
passivation and pitting-resistance properties of AISI 304L SS are clearly enhanced by SLA treatment.

Additionally, the paraboloidal patterned surface mainly remains hydrophobic after the polarization assay (Fig. 6, inset), even though its microstructure was overoxidized (i.e. the applied potential was higher than Epit). Besides, the cauliflower-like patterned sample (Fig. 6, inset) becomes less hydrophobic than the paraboloidal. However, the stability of the passive oxide layer in combination with the silane barrier coating is very high in comparison with flat samples.

\subsection{Electrochemical impedance spectroscopy with increasing immersion time in $\mathrm{NaCl}$}

\section{solution}

Analysis of Nyquist plots is a very difficult task when several interfaces and rough surfaces are present. In particular, consideration of both the Cassie-Baxter superhydrophobic surface and the semiconducting layer, which have been proved by contact angle and XPS measurements, respectively, is crucial to rationalize EIS results obtained from samples prepared using SLA. Fig. 7 represents the variation of the corrosion potential $\left(\mathrm{E}_{\mathrm{OCP}}\right)$ with the immersion time in $\mathrm{NaCl} 3.5 \mathrm{wt} . \%$ solution, as determined by EIS.

Our results confirm that bare flat SS samples suffers pitting corrosion after only $3 \mathrm{~h}$ of immersion in $\mathrm{NaCl}$ solution, as reflects the evolution to a more negative value of $\mathrm{E}_{\mathrm{OCP}}$ in Fig. 7. After $24 \mathrm{~h}$, both uncoated and silanized flat substrates exhibit a similar behavior in such aggressive medium. This feature indicates that deposition of a homogenous silane layer onto the flat surface is not enough for the SS protection since this coating is permeable to chloride anions after $24 \mathrm{~h}$ only After this short period of time, the silanized sample reaches the $\mathrm{E}_{\mathrm{OCP}}$ of the bare SS substrate. Pitting from crevice corrosion is also favored when the SS substrate is covered by an organic or inorganic film or by marine fouling organisms, which partially shield the access of oxygen to the surface but not of chloride anions. ${ }^{[1 \mathrm{~b}]}$ 
According to EIS results (Fig. 7), outstanding anticorrosion behavior was achieved with the silanized patterned substrates. The two studied surfaces were stable against pitting corrosion with increasing immersion time, even though this feature was particularly remarkable for samples with paraboloid-like micro-nano/structure. Thus, the $\mathrm{E}_{\mathrm{OCP}}$ of paraboloidal surfaces initially increases and, subsequently, keeps constant in the noble potential over time, which indicates superior passivity of the protecting layer on the surface. This behavior is in agreement with the initial polarization results (Fig. 6), which showed large passivating zones for both patterned surfaces. According to these observations, results allows us to conclude that oxidized, roughness and superhydrophobic microstructures are more effective against pitting corrosion than the smooth bare metal or the partially protected metal with a thin silane coating.

The impedance in the low frequency region reflects the charge transfer resistance, $R_{c t}$, and the double layer capacitance, $\mathrm{CPE}_{\mathrm{dl}}$. The Nyquist and Bode plots for each sample are presented in Fig. 8, while the electrical parameters are provided in the Supporting Information (Tables S2S5). Fig. 8a clearly evidences that the bare flat SS surface has a conductive behavior with a very low phase angle (i.e. close to zero degrees). The electrical equivalent circuit (EEC) fitted for that untreated AISIS 304L surface is illustrated in Fig. 9a. Due to the weakness of chromium passivating layer, the penetration of chloride anions across the pores increases with the immersion time, which gives place to the apparition of another capacitance (i.e. $\mathrm{CPE}_{\mathrm{p}}$ in Table S2). Besides, flat samples covered with a thin silane layer are more resistive than untreated flat SS, with a phase angle of around $48^{\circ}$ (Fig. 8b) at the initial immersion time. This result is in agreement with previous studies, which evidenced that thin silane coatings behave as soft barriers to water penetration. ${ }^{[19]}$ At the beginning of exposure to electrolyte, the silane monolayer actuates as a barrier. However, this protection is not permanent and a second time constant can be appreciated in Fig. 8 b (right) from -2 to 1 of $\log (f)$, as evidenced the appearance of a second loop at $24 \mathrm{~h}$. With increasing immersion time, both time constants 
converge into a single broad curve in the Bode plot, which has been associated to nonconducting corrosion products located under film, with high charge transfer resistance. The EEC for this system is depicted in exhibited in Fig. 9b, while the values of the different circuit elements are provided in Table S3.

Fig. 8c show that for the paraboloidal patterned surface the impedance value of $R_{c t}$ at low frequency increases from $11 \mathrm{k} \Omega \cdot \mathrm{cm}^{-2}$ to $21 \mathrm{k} \Omega \cdot \mathrm{cm}^{-2}$ after 7 days of immersion in $\mathrm{NaCl}$ solution (Table S4). Similarly, the impedance value of $\mathrm{R}_{\mathrm{ct}}$ at low frequency for the samples with cauliflower-like microstructure (Fig. 8d) increases from $12 \mathrm{k} \Omega \cdot \mathrm{cm}^{-2}$ to $119 \mathrm{k} \Omega \cdot \mathrm{cm}^{-2}$ after 7 days in $\mathrm{NaCl}$ (Table S5). This behavior can be attributed to a semiconducting material able to dissipate the electrons and ions diffusion, which maintains the surface in a "pseudopassivated" state and avoids the appearance of the pitting phenomenon. Moreover, the presence of entrapped air and the very thin silane layer coating the hydrophobic structure are responsible for the capacitance loop obtained at high frequency (Fig. 9c). Thus, the CassieBaxter stable state plays an important role, evidencing that AISI 304L SS surfaces can be protected from aggressive $\mathrm{NaCl}$ solutions the through oxidized layer, the patterning roughness and the hydrophobic property. Additional discussion about the temporal evolution of the charge transfer for given frequency, which is useful to understand the protection behavior close to the oxide-metal interface, is provided in the Supporting Information (Fig. S3).

\subsection{Mechanism of protection}

The chemical oxidation of the metal surface induced by the SLA treatment causes the formation of a beneficial and very stable magnetite rich phase $\left(\delta-\mathrm{Fe}_{3} \mathrm{O}_{4}\right)$ with a thick layer of adsorbed carbon oxide, as proved in previous work. ${ }^{[8]}$ These are responsible for the large passivating region observed in the polarization curves and for preserving the $E_{O C P}$ in the positive potential. This kind of passivating coating is well known as black iron oxide and is usually produced by chemical oxidation of steel in a process called "bluing" using an 
aggressive hot alkaline salt solution. The magnetite structure created by chemical oxidation or LSA is extremely resistant to corrosion because of its integration into the alloy structure forming a well adhered layer (i.e. similar to the alloying reaction between zinc and iron in the hot-dip galvanizing process). Moreover, the adherence and hydrophobic properties of this passivating coating are higher than those of simple barrier coatings formed by silane or organic paints. $^{[20]}$

The morphology and the wettability of the superhydrophobic surfaces play an important role in their resistance against corrosion. As the highly hydrophobic SS substrates studied in this work exhibit Cassie-Baxter stable state ${ }^{[12 a]}$ their excellent anti-pitting properties can be attributed not only to the semi-conducting properties of the outer carbonaceous layer but also to the presence of stable air trapped between the peaks and dales of the micro-nano patterns. The latter effect has also been reported for other metals. ${ }^{[21,22]}$ For example, in a recent study devoted to examine the corrosion resistance of aluminum alloy treated with chemical vapor deposition, Zhang et al. ${ }^{[22]}$ concluded that Cassie-Baxter patterned surfaces are more resistant to corrosion than Wenzel morphologies. Moreover, an organic-inorganic silane coating was also used in such study to induce a surface wettability change from hydrophilic to hydrophobic. ${ }^{[22]}$ Overall, those observations are fully consistent with the protection mechanism proposed in this work.

Solid state properties of passive and oxide films formed after SLA treatment have been determined and correlated with the stability of the passive films. The breakdown in the passive layer on SS is mainly controlled by electronic and ionic transport processes. ${ }^{[23]}$ Therefore, the excellent anti-pitting behavior of superhydrophobic 304L SS in NaCl solution has been attributed to the synergistic combination of the following factors: $(i)$ the great adherence of oxide passivating layer; (ii) the presence of the magnetite structure combined with the carbonaceous layer, which behave as a n-type semiconductor; (iii) the presence of air among the well-defined and ordered structure produced by the SLA process (i.e. the beneficial 
effect of the Cassie-Baxter stable state); and (iv) the thin organosilane network that provides very low wettability to the passive coating.

\section{Conclusions}

AISI 304L SS with anti-pitting properties has been achieved by applying a femtosecond SLA treatment to generate micro-nano structures on the surface and, subsequently, depositing an organofluorine nanometric coating. As a result, highly hydrophobic surfaces with paraboloidad and cauliflowered patterns have been obtained. The paraboloidal patterned structure, mainly formed by highly oriented $\mathrm{Fe}_{3} \mathrm{O}_{4}$ building blocks assembled into knurled structures, ${ }^{[24]}$ offers more resistance to morphology changes than the more globular structures characteristics of the cauliflower-like superhydrophobic surface. However, both micro- and nanometric spherical magnetite structures homogenously obtained after laser ablation are efficient to avoid 304L SS pitting corrosion. Polarization and EIS studies suggest that the antipitting behavior of the patterned structures is probably due to the thick layer of regularly distributed iron oxides combined with a carbonaceous coating above the metal surface, caused by the SLA treatment. In general, two significant conclusions can be extracted from the present study:

- Highly hydrophobic rough micro-nano patterned structures obtained after SLA treatment are more resistant to pitting corrosion than the chromium passivated surface of bare and flat AISI 304L SS.

- The silane coating is not impermeable enough to protect the polished bare metallic surface from the electrolytic attack from an aggressive saline solution.

Additionally, the formation of a compact protective oxide layer composed of iron, chromium and carbon has been found to be an important advantage of the SLA treatment, which also contributes eliminating the defects of the pure magnetite crystalline layer and providing less porosity to the passive coating. 
In summary, the approach presented in this work represents an attractive alternative for applications in microengineering, for example protecting small parts of fuel cells, solar cells, biomedical tools for surgery (needles) and others surfaces against the pitting corrosion caused by an aggressive media or by acid physiological fluids.

Received: ((will be filled in by the editorial staff)) Revised: ((will be filled in by the editorial staff)) Published online: ((will be filled in by the editorial staff))

_[1] a) H. H. Uhlig, R. Winston, Corrosion and corrosion control: An introduction to corrosion science and engineering, 4th ed., John Wiley \& Sons, Inc., Hoboken New Jersey, 2008, pp. 333-365; b) M. da Cunha Belo, B. Rondot, C. Compere, M. F. Montemor, A. M. P. Simões, M. G. S. Ferreira, Corros. Sci. 1998, 40, 481.

_[2] J. E. Singley, Review of monitoring, detection, prevention and control techniques, in: Corrosion Prevention and Control in Water Treatment and Supply Systems, Noyes Publications, New Jersey, 1985, pp. 155-157.

_[3] W. Schwenk, in Fundamentals and Concepts of Corrosion and Electrochemical Corrosion Control, Handbook of Cathodic Corrosion Protection (Eds: W. von Baeckmann, W. Schwenk, W. Prinz), 3rd Ed., Gulf Publishing Co., Houston, 1997, pp. 27-76.

_[4] V. S. Sastri, E. Ghali Sastri, Materials: Metals, Alloys, Steels and Plastics, in: Corrosion Prevention and Protection. Practical Solutions, John Wiley \& Sons Ltd., West Sussex, 2007, pp. 214-227.

_[5] O. Knudsen, A Forsgren, Corrosion control through organic coatings, Taylor \& Francis Group, Boca Raton, 2006.

_[6] a) O. V. Akgün, M. Ürgen, A. F. Cakir, Mater. Sci. Eng. A 1995, 203, 324; b) O. V. Akgün, O. T. Inal, O. T. J. Mater. Res. 1995, 30, 6105; c) A. Conde, I. Garcia, J. J. de 
Damborenea, Corros. Sci. 2001, 43, 817; d) P. H. Chong, Z. Liu, X. Y. Wang, P. Skeldon, PThin Solid Films 2004, 453, 388.

_[7] W. Pacquentin, N. Carona, R. Oltra, Appl. Surf. Sci. 2014, 288, 34.

_[8] A.-M. Kietzig, S. G. Hatzikiriakos, P. Englezos, Langmuir 2009, 25, 4821.

_[9] a) Y. Tamaura, M. Tabata, Nature 1990, 346, 255; b) C.-L. Zhang, S. Li, L.-J. Wang, T.-H. Wu, S.-Y. Peng, Mater. Chem. Phys. 2000, 62, 44; c) C.-L. Zhang, S. Li, L.-J. Wang, T.-H. Wu, S.-Y. Peng, Mater. Chem. Phys. 2000, 62, 52.

_[10] a) M. Honkanen, M. Hoikkanen, M. Vippola, J. Vuorinen, T. Lepistö, P. Jussila, H. Ali-Löytty, M. Lampimäki, M. Valden, Appl. Surf. Sci. 2011, 257, 9335; b) V. Dalmoro, J. H. Z. dos Santos, E. Armelin, C. Alemán, D. S. Azambuja, Appl. Surf. Sci. 2013, 273, 758; c) J. I. Iribarren-Mateos, I. Buj-Corral, J. Vivancos-Calvet, C. Alemán, J. I. Iribarren, E. Armelin, Prog. Org. Coat., 2015, 81, 47.

_[11] S. Curran, K.-S. Liao, N. Alley, A. Haldar, A. Wang, R. Tatarin, R. Waterproof coating with nanoscopic/microscopic features, WO 2014186454 A1, 2014.

_[12] a) S. Moradi, S. Kamal, P. Englezos, S. G. Hatzikiriakos, Nanotechnology 2013, 24, 415302; b) S. Moradi, S. Kamal, S. G. Hatzikiriakos, Surf. Innov. 2015, 3, 151.

_[13] J. Drelich, Surf. Innov. 2013, 1, 248.

_[14] M. P. Quiroga-Argañaraz, J. M. Ramallo-López, G. Benítez, A. Rubert, E. D. Prieto, L. M. Gassa, R. C. Salvarezza, M. E. Vela. Phys. Chem. Chem. Phys. 2015, 17, 14201.

_[15] M. Ma, Y. Zhang, W. Yu, H.-Y. Shen, H.-Q. Zhang, N. Gu, Coll. Surf. A. Phys. Eng. Aspects 2003, 212, 219.

_[16] T. D. Glotch, M. D. Kraft, Phys Chem Minerals 2008, 35, 569.

_[17] T. Nishimura, H. Katayama, K. Noda, T. Kodama, Corrosion 2000, 56, 935.

_[18] a) D. J.Miller, M. C. Biesinger, N. S. McIntyre, Surf. Interface Anal. 2002, 33, 299; b) H. Piao, N. S. McIntyre, Surf. Interface Anal. 2002, 33, 591. 
_[19] a) V. Dalmoro, J. H. Z. dos Santos, I. M. Baibich, I. S. Butler, E. Armelin, C. Alemán, D. S. Azambuja, Prog. Org. Coat. 2015, 80, 49; b) Y. Wang, E. Watkins, J. Ilavsky, T. L. Metroke, P. Wang, B. Lee, D. W. Schaefer, J. Phys. Chem. B 2007, 111, 7041; c) Y. Wang, P. Wang, D. Kohls, W. A. Hamilton, D. W. Schaefer, Phys. Chem. Chem. Phys. 2009, 11, 161. _[20] a) L. Tan, Y. Yang, T. R. Allen, Corros. Sci. 2006, 48, 3123; b) M. J. Kreder, J. Alvarenga, P. Kim, J. Aizenberg, Nature Rev. 2016, 1, 1.

_[21] a) T. Liu, S. G. Chen, S. Cheng, J. T. Tian, X. T. Chang, Y. S. Yin, Electrochim. Acta 2007, 52, 8003; b) T. Ishizaki, J. Hieda, N. Saito, O. Takai, Electrochim. Acta 2010, 55, 7094;

c) P. Wang, D. Zhang, R. Qiu, Corros. Sci. 2012, 54, 77.

_[22] K. Zhang, J. Wu, P. Chu, Y. Ge, R. Zhao, X. Li, Int. J. Electrochem. Sci. 2015, 10, 6257.

_[23] N. E. Hakiki, Corros. Sci. 2011, 53, 2688.

_[24] R. Liu, Y. Zhao, R. Huang, Y. Zhao, H. Zhou, Cryst. Eng. Comm. 2010, 12, 4091. 


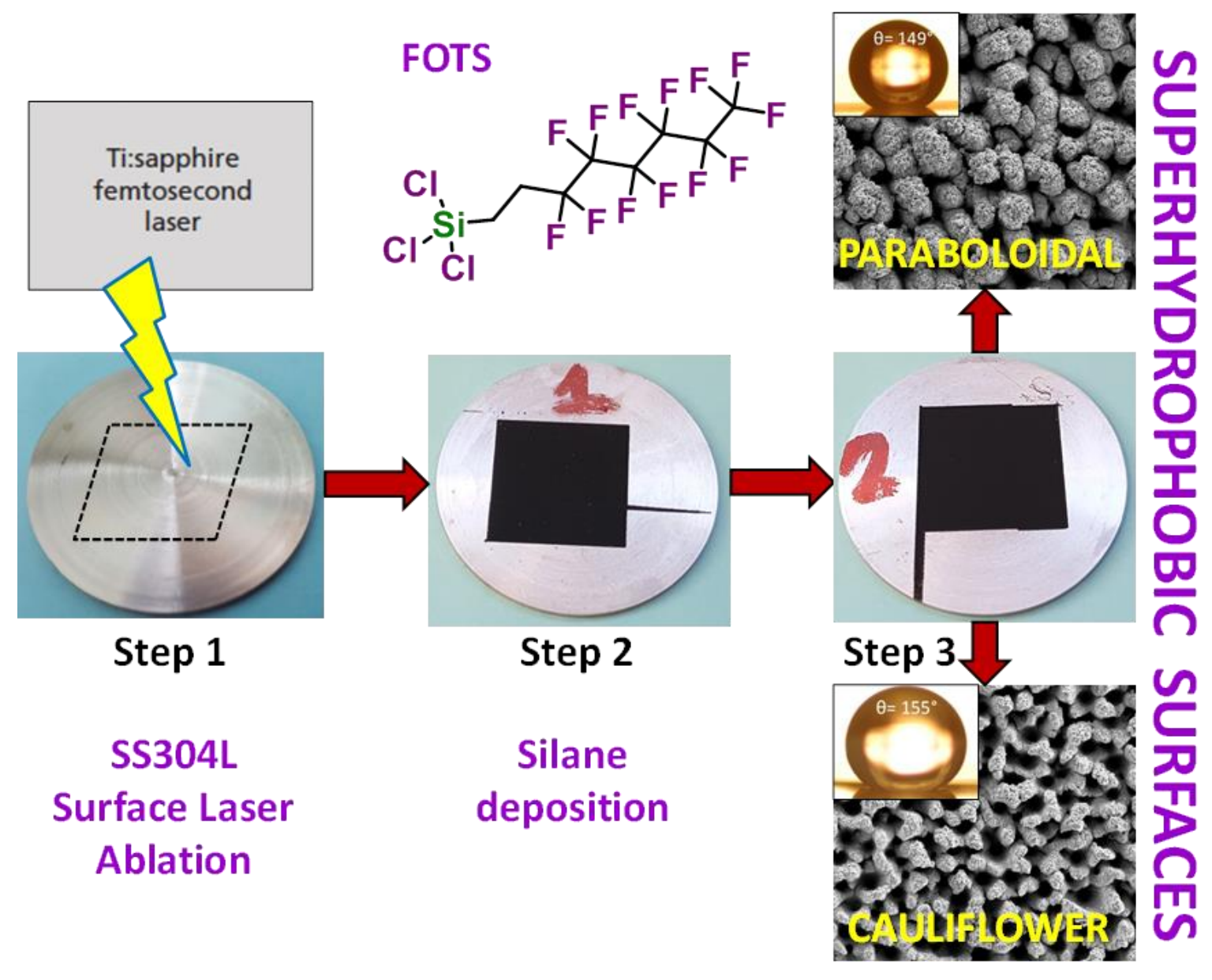

Fig. 1. Schematic representation of the methods applied to produce superhydrophobic SS substrates: SLA and sol-gel deposition. 

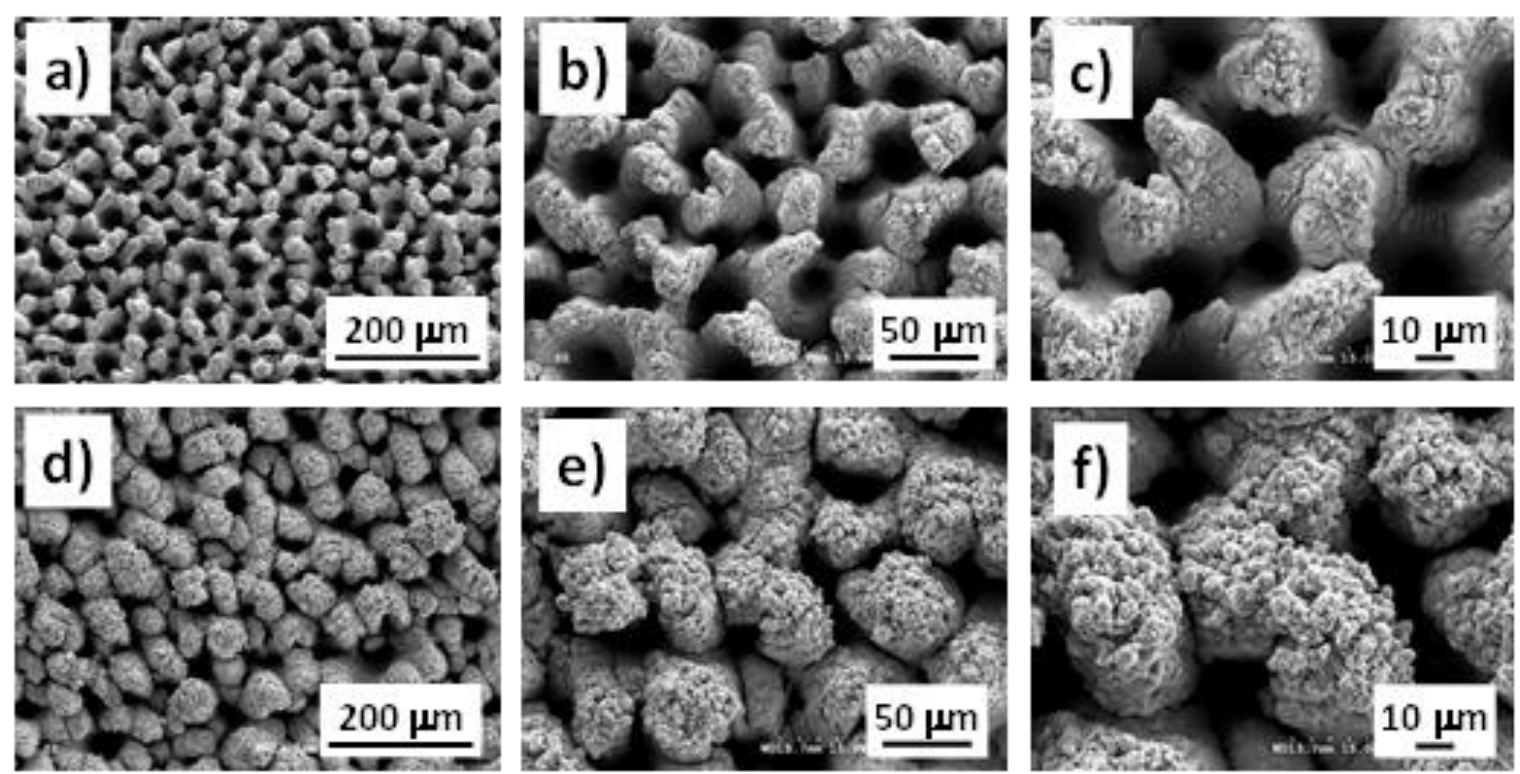

Fig. 2. SEM images (three levels of magnification) of two SS surface patterns: (a-c) Paraboloidal pattern obtained using $\Phi_{0}=16 \mathrm{~J} / \mathrm{cm}^{2}$ and $V=460 \mu \mathrm{m} / \mathrm{s} ;(d-f)$ Cauliflowered pattern obtained using $\Phi_{0}=135.8 \mathrm{~J} / \mathrm{cm}^{2}$ and $V=930 \mu \mathrm{m} / \mathrm{s}$. 

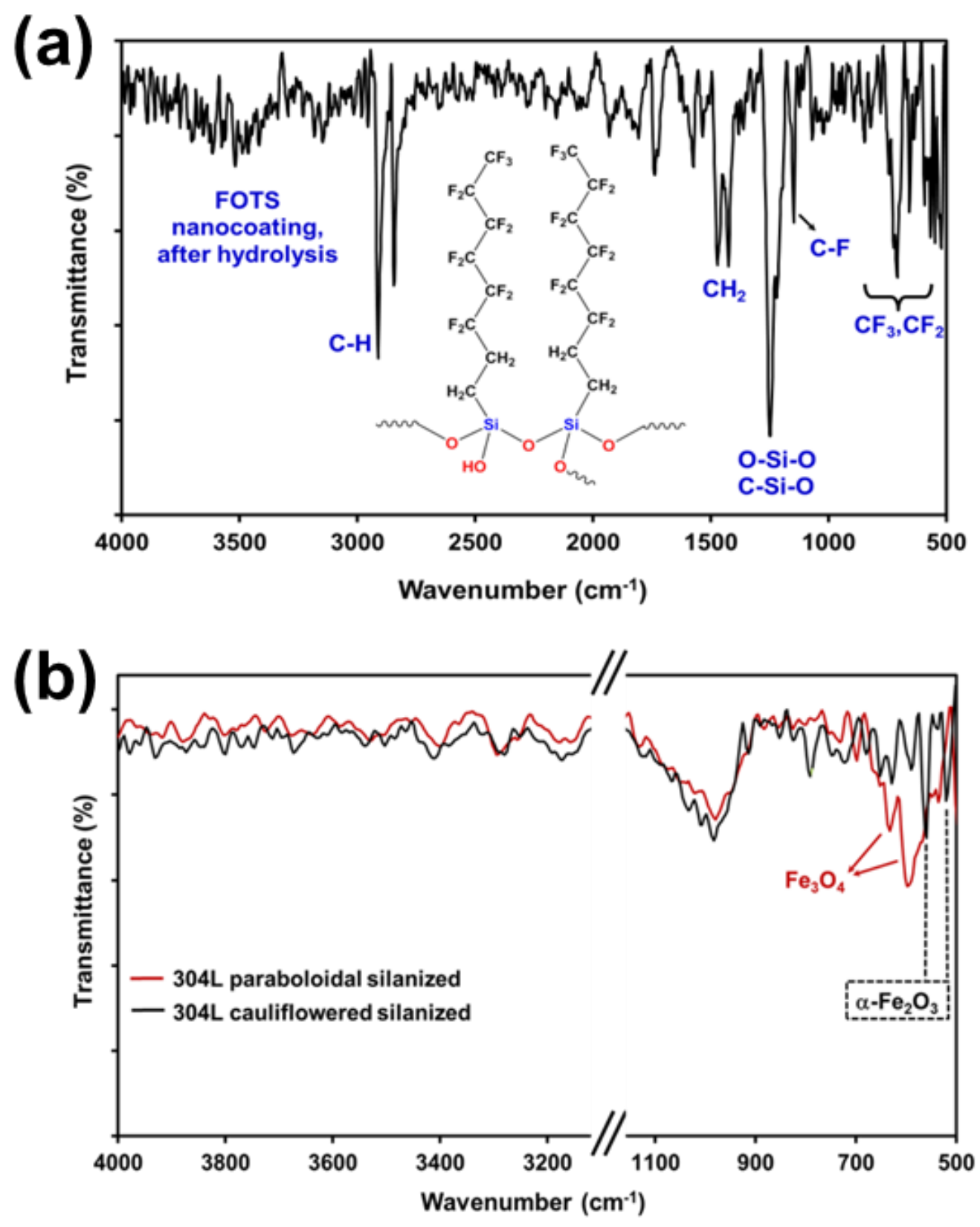

Fig. 3. FTIR spectra of: (a) silanized flat AISI 304L sample before corrosion assays; and (b) silanized paraboloidal and cauliflower-like patterned surfaces after corrosion assays. 

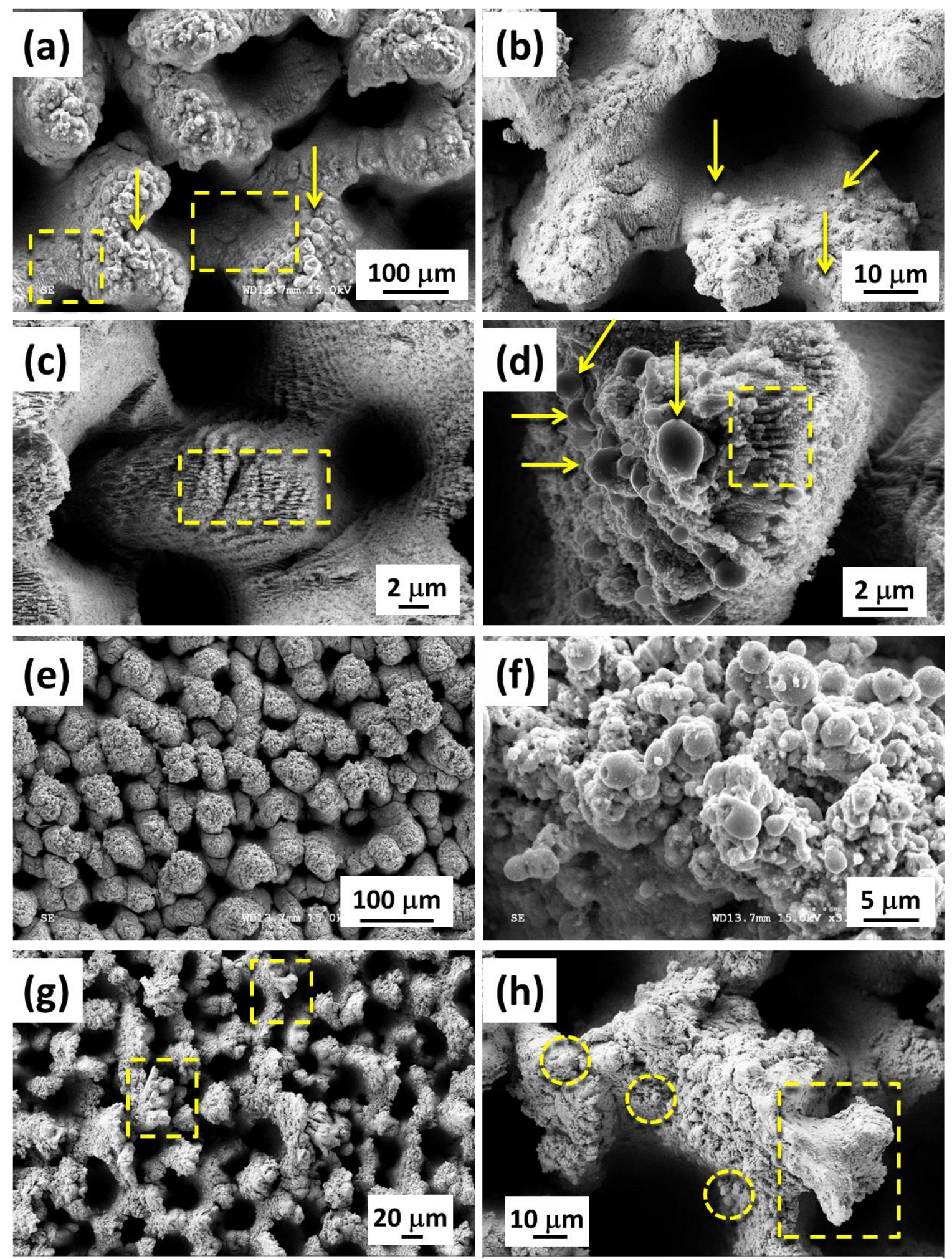

Fig. 4. SEM images of silanized (a-d) paraboidal and (e-h) cauliflowered SS samples. Images (a) and (e) correspond to samples before immersion assays, while images $(c, d, e)$ and $(f, g, h)$ correspond to samples after immersion in $\mathrm{NaCl} 3.5 \mathrm{wt}$. \% solution for 7 days. 
(a)
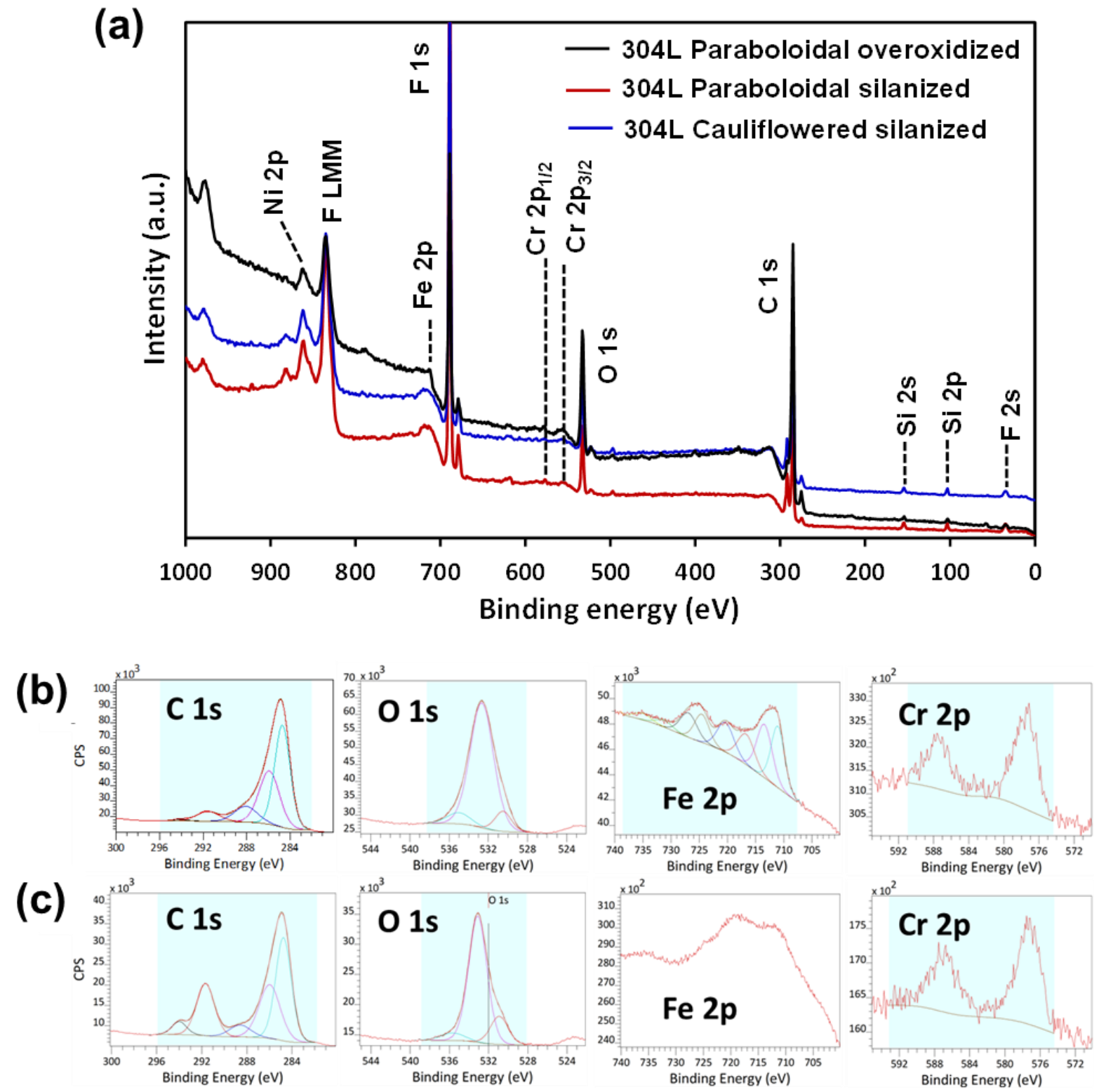

(d)
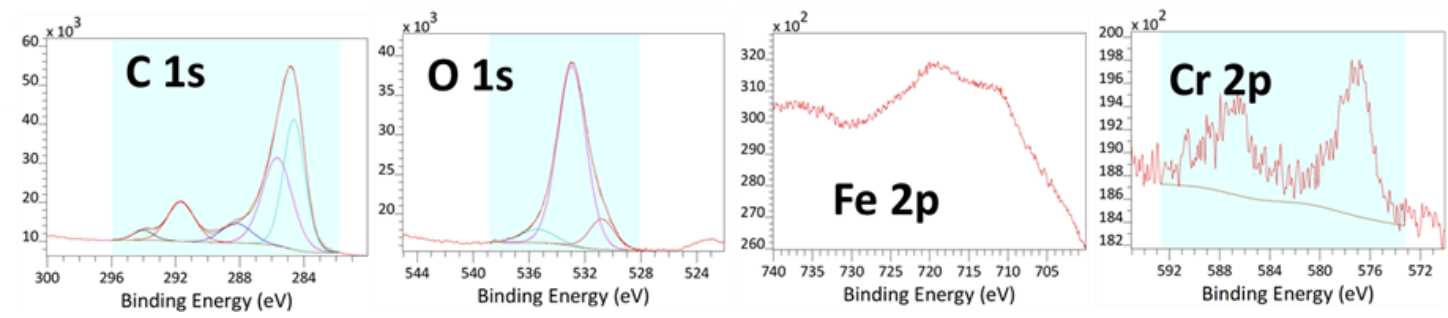

Fig. 5. (a) XPS survey spectra of SS silanized samples with paraboloid-like surface after potentiodynamic polarization from -1.0 to $+1.0 \mathrm{~V}$ in $\mathrm{NaCl} 3.5 \mathrm{wt}$. \% solution ("overoxidized" sample) and after static immersion in $\mathrm{NaCl} 3.5$ wt. \% solution for 7 days, and cauliflower-like surface after immersion in $\mathrm{NaCl}$ for 7 days. (b-d) XPS high resolution spectra of: $(b)$ the overoxidized sample, and both (c) the paraboloidal and $(d)$ cauliflowered samples after static immersion. Atomic \% for each atom is presented in Table S1. 


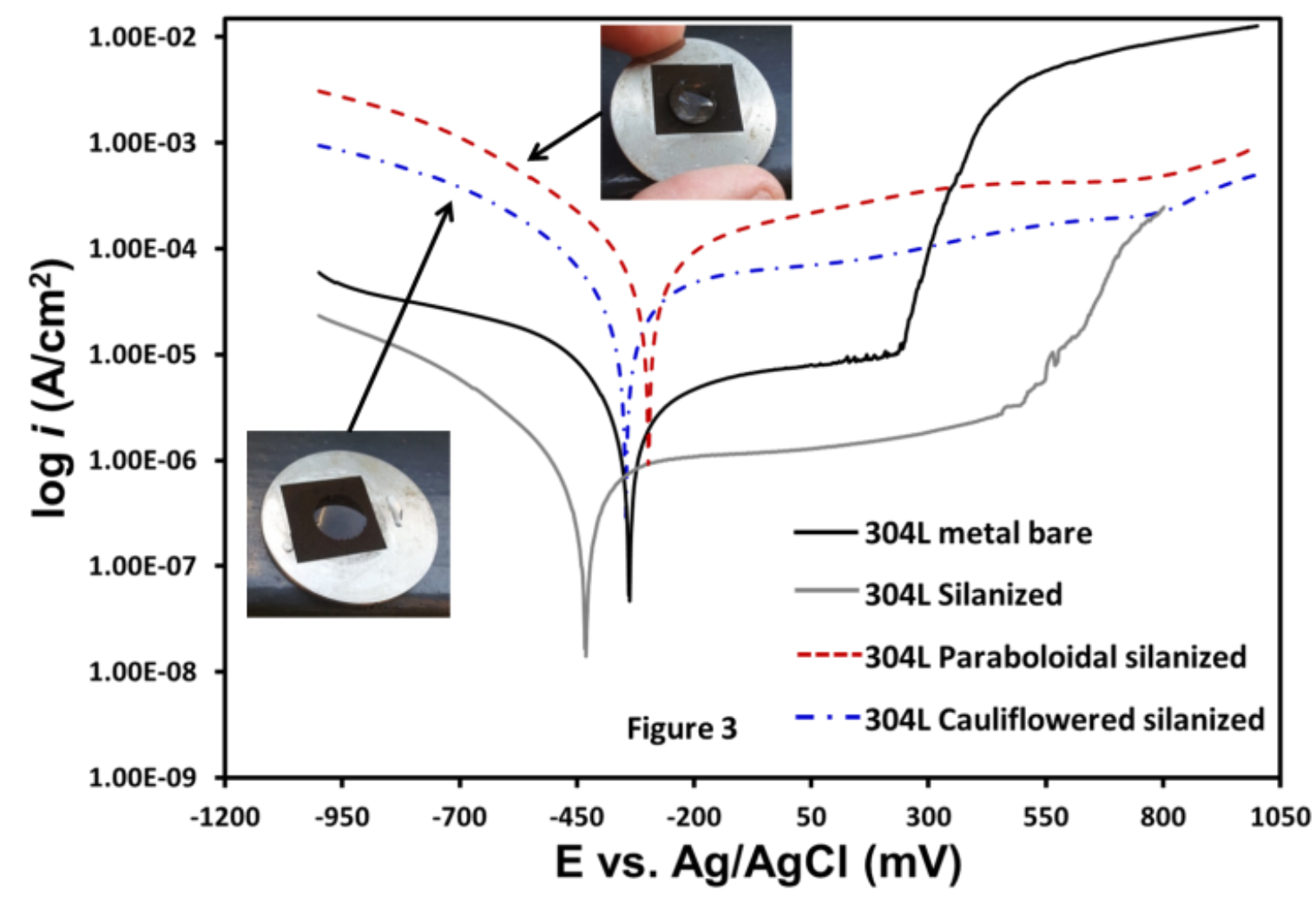

Fig. 6. Tafel polarization plots of AISI 304L SS samples in NaCl $3.5 \mathrm{wt}$. \% solution: bare flat, silanized flat, silanized paraboloidal and silanized cauliflowered surfaces. Images (insets) correspond to the silanized paraboloidal (upper) and silanized cauliflowered (down) samples after the polarization assays. 


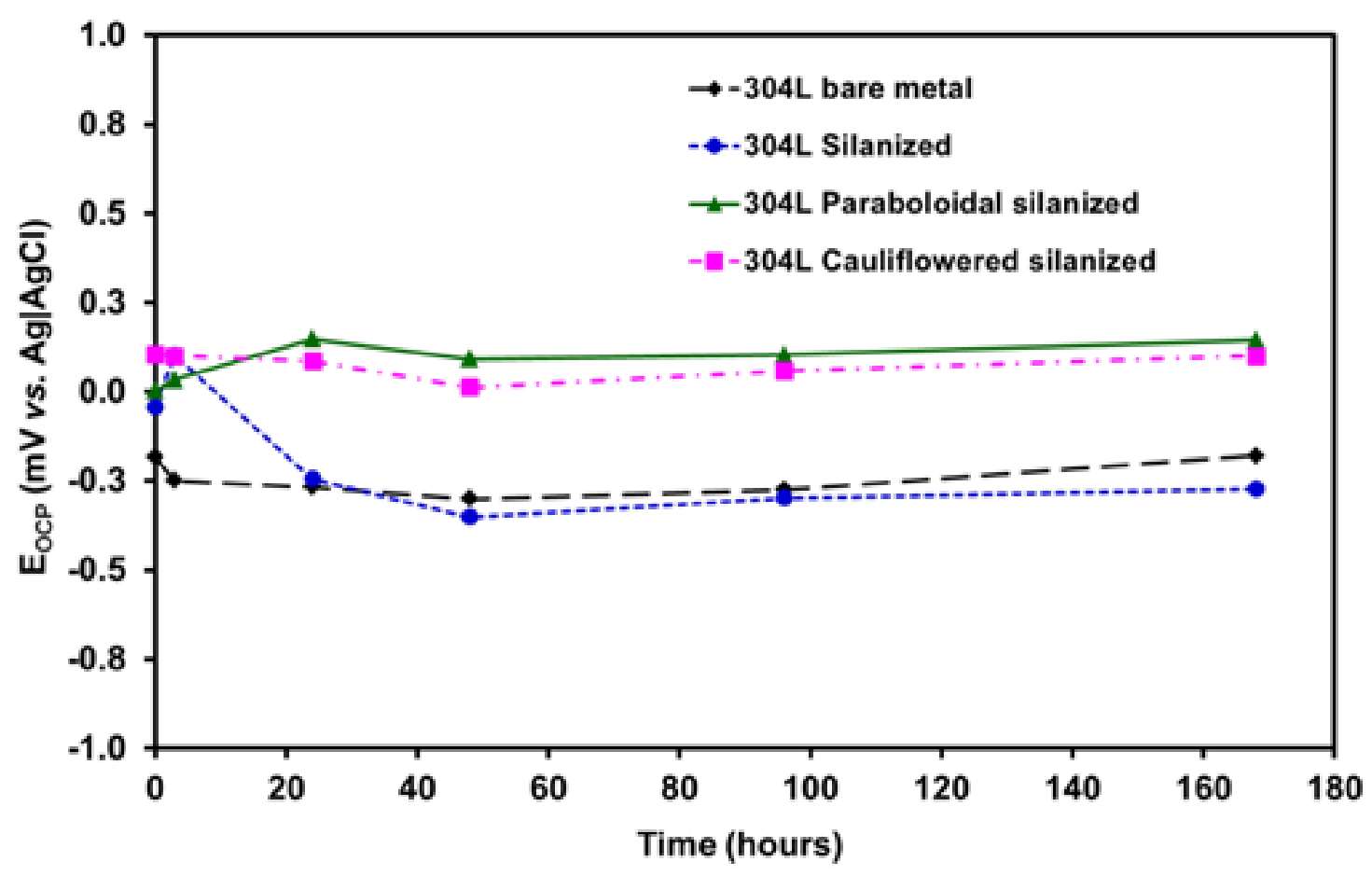

Fig. 7. Evolution of corrosion potential (EOCP) with the immersion time in NaCl $3.5 \mathrm{wt}$. \% solution determined by EIS for bare flat, silanized flat, silanized paraboloidal and silanized cauliflowered samples. 
(a)

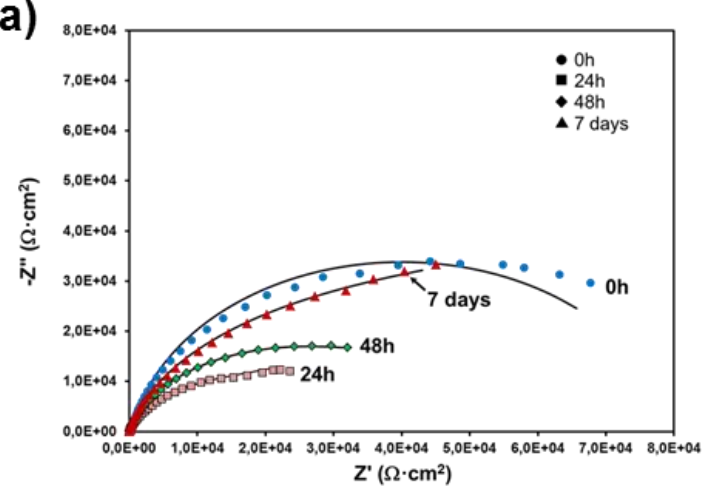

(b)

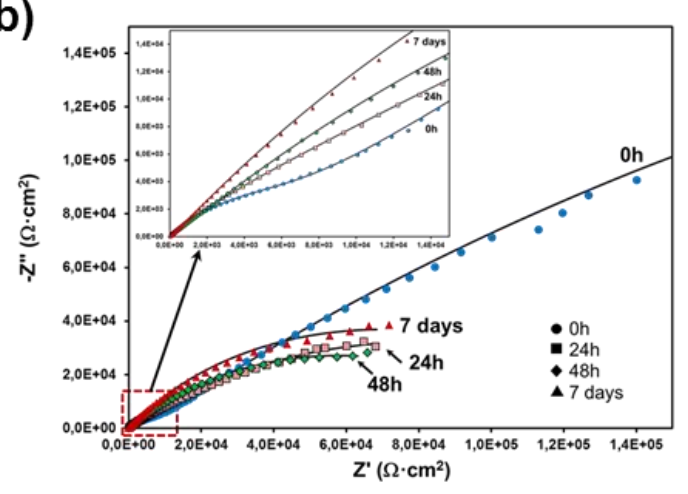

(c)

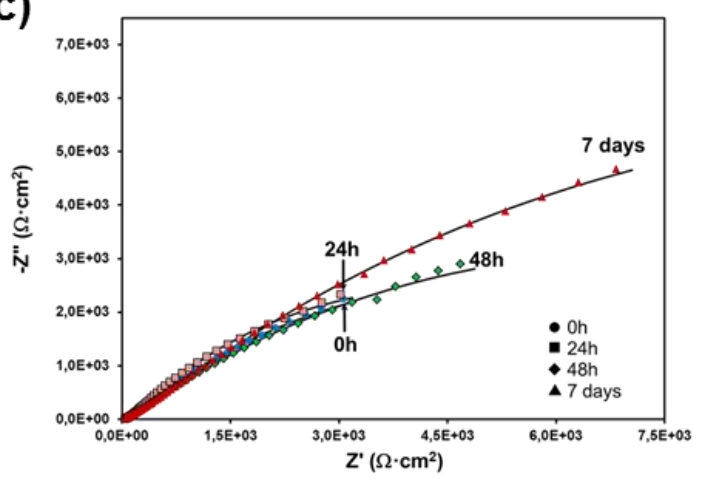

(d)

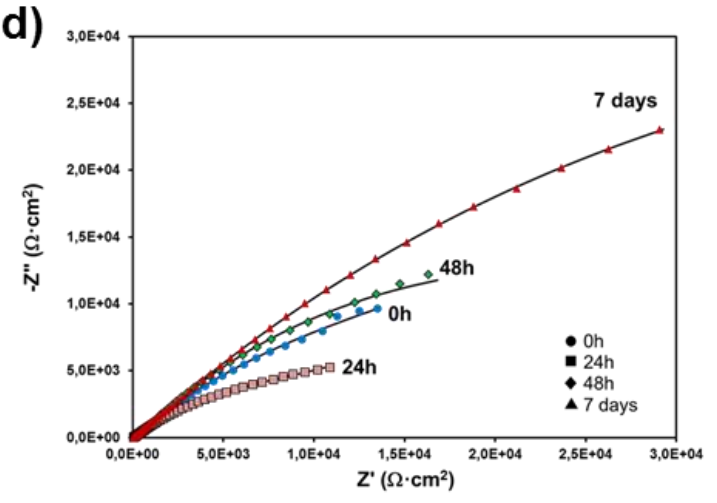

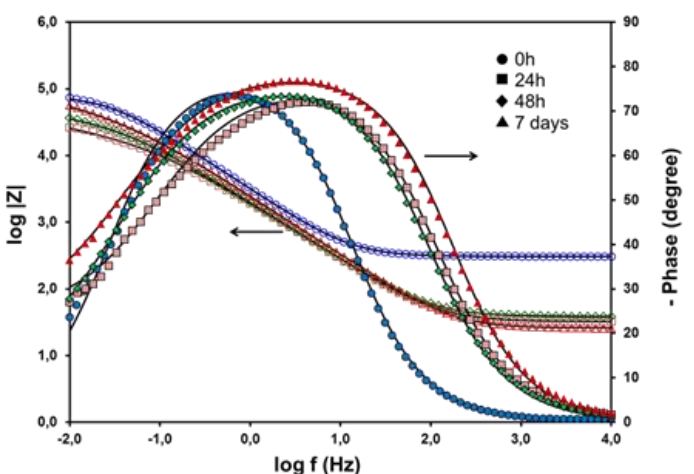
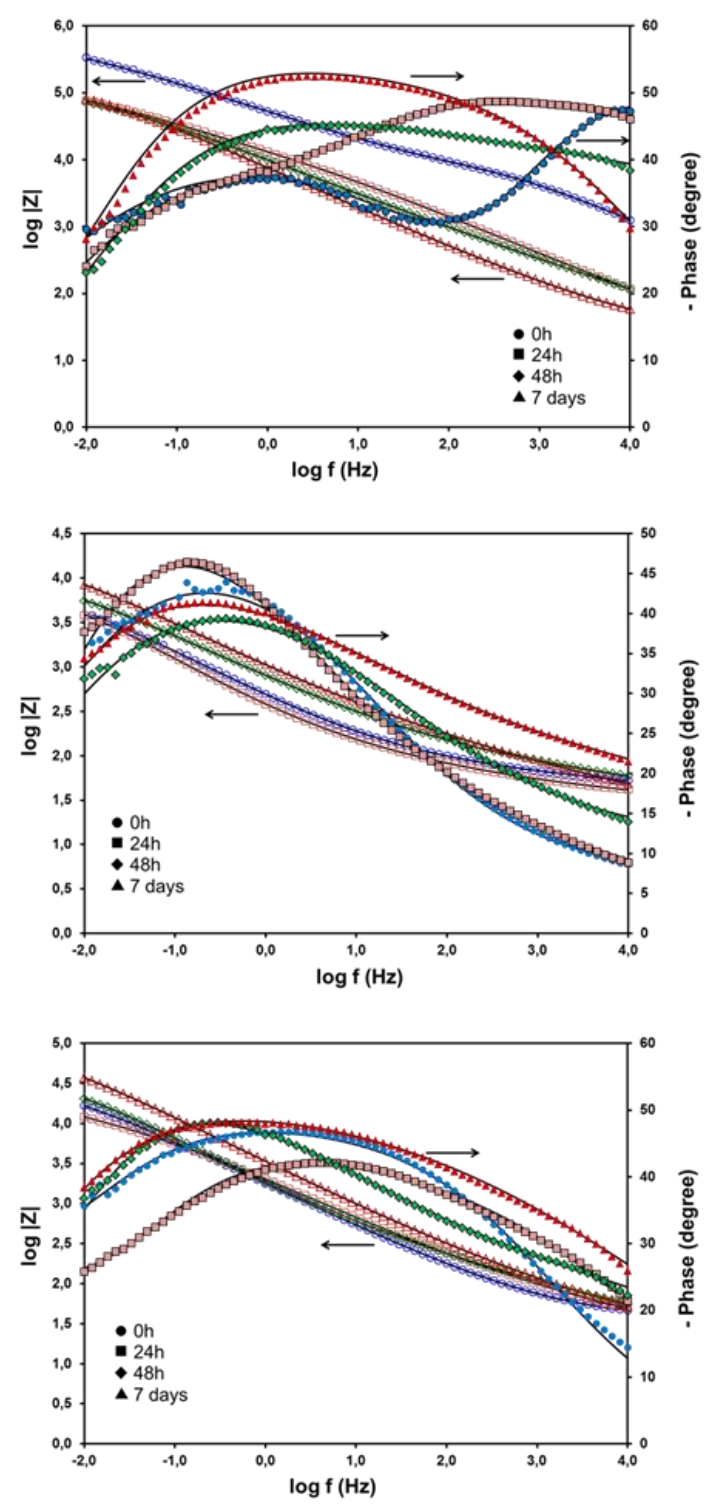

Fig. 8. Evolution of the Nyquist (left) and Bode (right) plots for (a) bare flat, (b) silanized flat, (c) silanized paraboloidal patterned, and (d) silanized cauliflowered patterned SS samples with the increasing immersion time in $\mathrm{NaCl} 3.5 \mathrm{wt}$. \% solution. The inset in the left figure of (b) corresponds to the enlargement of the impedance data at high frequency. 
(a)

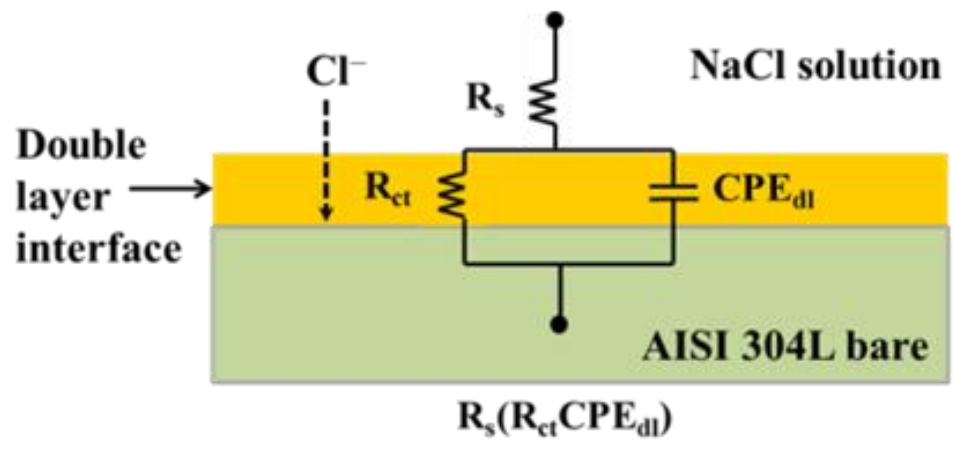

(b)

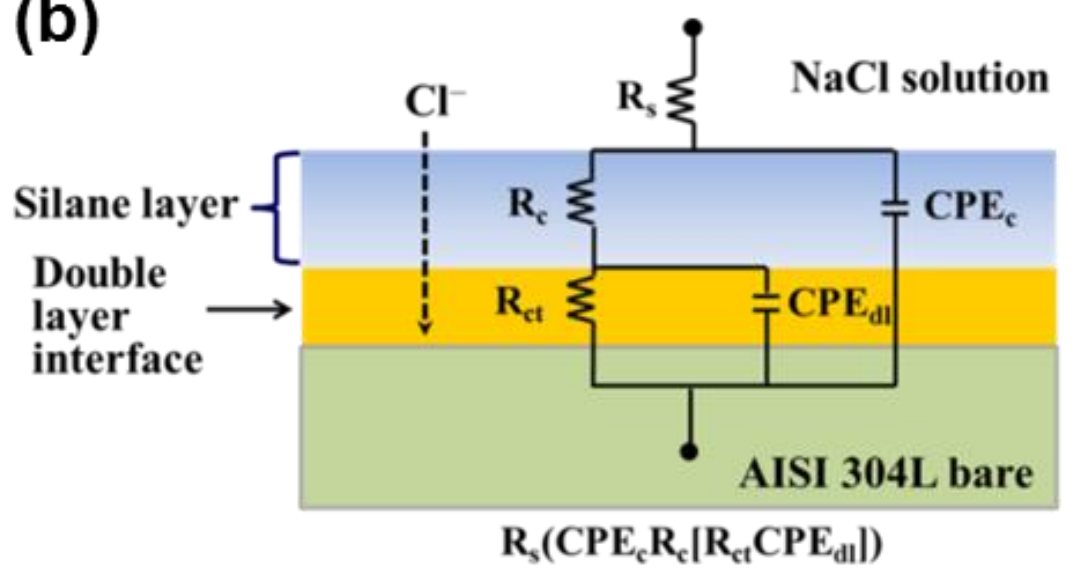

(c)

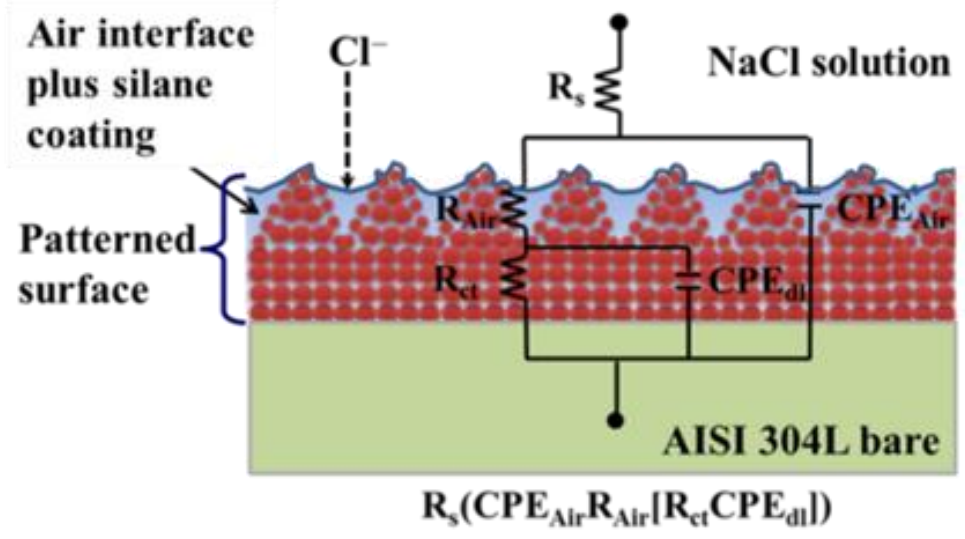

Fig. 9. Schematic representation of the most important interfaces and EEC of each system: (a) bare flat, (b) silanized flat and (c) silanized patterned (paraboloid-and cauliflower-like) SS samples. The thickness of the represented layers does not correspond to the real scale. 
Table 1. CA and CA hysteresis of SS samples fabricated by surface laser ablation.

\begin{tabular}{lll}
\hline AISI 304L Surface Condition & ${\mathrm{CA}\left({ }^{\mathrm{o}}\right)^{[\mathrm{a}]}}$ & $\mathrm{CA}$ hysteresis $\left(^{\mathrm{o}}\right)^{[\mathrm{a}]}$ \\
\hline Bare & 80 & 52 \\
Silanized & 108 & 35 \\
Paraboloidal pattern silanized $^{[\mathrm{b}]}$ & 145 & 16 \\
Cauliflowered pattern silanized $^{[\mathrm{b}]}$ & 157 & $<5$ \\
\hline
\end{tabular}

[a] Standard deviations were lower than $2^{\circ}$ in all cases. ${ }^{[b]}$ The contact angle of non-silanized patterned samples (i.e. after laser ablation) is nearly zero as the droplet is readily spreading and, therefore, measurement of the contact angle hysteresis is not possible. The time interval between the surface laser ablation treatment and starting of the silanization treatment was lower than two days in all cases. 
Table 2.Tafel parameters obtained for flat and patterned AISI 304L SS surfaces in NaCl 3.5 wt. \%.

\begin{tabular}{llllll}
\hline Surface condition & $\begin{array}{l}\mathrm{E}_{\text {corr }} \\
(\mathrm{mV})\end{array}$ & $\begin{array}{l}\mathrm{E}_{\mathrm{pit}} \\
(\mathrm{mV})\end{array}$ & $\begin{array}{l}\mathrm{i}_{\text {corr }} \\
\left(\mathrm{A} / \mathrm{cm}^{2}\right)\end{array}$ & $\begin{array}{l}\mathrm{E}_{\text {pas }} \text { range } \\
(\mathrm{mV})\end{array}$ & $\begin{array}{l}\Delta \mathrm{E}_{\mathrm{pas}} \\
(\mathrm{mV})\end{array}$ \\
\hline Bare flat & -338 & +238 & $5.75 \times 10^{-6}$ & -98 to +328 & 336 \\
Silanized flat & -440 & +452 & $9.20 \times 10^{-7}$ & -288 to +589 & 633 \\
Silanized paraboloidal & -298 & +841 & $1.22 \times 10^{-5}$ & -36 to +841 & 877 \\
Silanized cauliflowered & -346 & +781 & $5.85 \times 10^{-5}$ & -70 to +781 & 851 \\
\hline
\end{tabular}


The table of contents entry.

E. Armelin, ${ }^{*}$ S. Moradi, S. G. Hatzikiriakos, ${ }^{*}$ C. Alemán*

Designing Stainless Steel Surfaces with Anti-Pitting Properties Applying Laser Ablation and Organofluorine Coatings

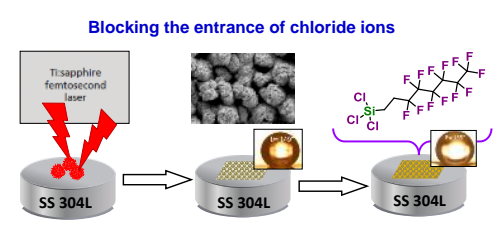

Long-lasting and superhydrophobic stainless steel with anti-pitting properties is achieved by modifying conventional AISI 304L through a two-step strategy consisting on (i) application of a femtosecond surface laser ablation treatment to generate micro-nano structures on the surface; and (ii) deposition of organofluorine nanometric coating. Results prove that the stainless steel surface acquires efficient anticorrosive properties due to the homogenization and refinement of the patterned microstructure into a magnetite rich phase, in combination with the formation of a carbonaceous and sol-gel layer. The prepared superhydrophobic surfaces prevent the steel substrates from getting wet with water, protecting them from the pitting corrosion caused by the electrolyte intrusion. 